\title{
Peningkatan Unjuk Kerja Pada Link Microwave Menggunakan Teknik Diversity Maximal Ratio Combining
}

\author{
Debbi Irfan Mudhoep ${ }^{1}$, Rukmi Sari Hartati ${ }^{2}$, Yoga Divayana ${ }^{3}$ \\ [Submission: 11-02-20209, Accepted: 05-12-2020]
}

\begin{abstract}
In a communication system using microwave waves (microwave links), noise and multipath fading can reduce and reduce the performance of the communication system. The propagation of microwaves is influenced by several things in the reception system, apart from having to LOS (Line Of Sight), there is a signal reflection from the surface that causes interference (multipath signal). By using the technique of maximum diversity ratio combining on systems that are exposed to noise and fading is used through BER (Bit Error Rate) analysis. Research on BER in AWGN channel with QPSK modulation using MRC technique for 3 times treatment with BER value of $20.05 \mathrm{~dB}, 14.86 \mathrm{~dB}, 12.12 \mathrm{~dB}$. BER testing concludes that MRC technique can improve performance on microwaves
\end{abstract}

Intisari- Pada system komunikasi menggunakan gelombang microwave ( link microwave), adanya noise serta multipath fading dapat mengurangi dan menurunkan kinerja system komunikasi. Perambatan gelombang mikro dipengaruhi beberapa hal pada system penerimaan selain harus LOS ( Line Of Sight ) terdapat sinyal pantulan dari permukaan yang sangat menimbulkan interferensi ( sinyal multipath ). Dengan menggunakan teknik diversity maximal ratio combining pada system yang terkena noise dan fading digunakan melalui analisa BER ( Bit Error Rate ). Penelitian BER di kanal AWGN dengan modulasi QPSK menggunakan teknik MRC sebanyak 3 kali perlakuan nilai BER sebesar $20.05 \mathrm{~dB}, 14.86 \mathrm{~dB}, 12.12 \mathrm{~dB}$. Pengujian BER memberikan kesimpulan teknik MRC mampu meningkatkan kinerja pada gelombang mikro.

Kata Kunci - Maximal Ratio Combining, Noise, Multipath Fading, BER

\section{PENDAHULUAN}

Teknologi wireless yang menggunakan gelombang frekuensi sebagai penghantar dalam transmisi data merupakan salah satu metode pengiriman sinyal selain media fisik seperti tembaga dan serat optic.

Pada penggunaan system komunikasi gelombang mikro terdapat penggunaan berbagai antenna yang ada di sekitar pengirim dan penerima sehingga dapat menyebabkan adanya multipath fading yang sangat mengurangi daya sinyal saat ditransmisikan. Secara garis besar transmisi melalui kanal wireless terdapat hal-hal yang bias menyebabkan penurunan kualitas informasi yaitu noise dan fading [1].

${ }^{I}$ Guru, Kompetensi Keahlian Teknik Komputer dan Jaringan, SMKN 1 Bangli, Jln.Brigjen Ngurah Rai, Bangli, Bali 80613 INDONESIA (tlp: 0361-91091; e-mailirfandeb@yahoo.com)

${ }^{2,}{ }^{3}$ Dosen, Program Pasca Sarjana, Magister Teknik Elektro, Fakultas Teknik Universitas Negeri Udayana, Jln. P.B. Sudirman, Denpasar, Bali 80232 INDONESIA (tlp: 0361239599; e-mail: ${ }^{2}$ rukmisari@unud.ac.id, ${ }^{3}$ yoga@unud.ac.id )
Namun dalam penerimaan memang tidak hanya sinyal LOS (Line Of Sight ) yang berperan dalam penurunan kualitas melainkan sinyal yang terpantul akibat tumbuhan, gedung, batu bahkan efek yang ditimbulkan oleh penghalang inilah yang disebut dengan multipath. Pelemahan atau fluktuasi sinyal inilah yang disebut dengan fading hingga menggunakan jalan yang berbeda sehingga menyebabkan interferensi.

Hal ini menyebabkan adanya penurunan kualitas penerimaan informasi ditambah lagi masalah tersebut bersifat acak dan tidak bisa pasti jenis masalahnya. Sehingga diperlukan suatu teknik untuk memperbaiki kualitas sinyal agar didapatkan sinyal dengan kualitas baik pada penerima [2][3]. Signal to noise Ratio (SNR), Bit Error Rate (BER), dan Q-factor merupakan parameter kunci yang menentukan performa suatu channel komunikasi [4]. Sedangkan titik pada lintasan yang memiliki loss yang sangat besar menyebabkan kualitas komunikasi menurun [5]. Multipath fading ini memberikan pengaruh pada sinyal penerimaan baik secara menguat ataupun melemah dimana efek yang ditimbulkan sangat mempengaruhi kualitas komunikasi. Sebagaimana efek yang sering terjadi seperti difraksi, pengahamburan, attenuasi, dan dari gelombang mikro. Jika dalam suatu jaringan terdapat link yang terputus, maka jalur tersebut masih dapat terhubung tanpa memengaruhi konektivitas perangkat pada jalur tersebut [6]. Untuk mengatasi efek fading, dapat dilakukan optimasi dengan menggunakan teknik diversity. Terdapat beberapa jenis teknik diversity pada jaringan gelombang mikro salah satunya adalah teknik combining.

Teknik kombining memberikan mengkombinasikan sinyal informasi yang memiliki pemicu sama dengan fading yang berbeda sehingga menjadikan satu sinyal informasi sebagai hasil kombinasi. Pada penelitian ini menggunakan simulasi yang menerapkan teknik diversity maximal ratio combining agar menghasilkan unjuk kerja transmisi di elombang ikro ketika mendapat pengaruh dari noise dan multipath fading

Pada penerapan semua kondisi kanal fading, skema Maximal Ratio Combining memiliki gain diversity paling tinggi dan Selection Combining memiliki gain diversity paling rendah [7]

Untuk mengatasi konsep multiple antena yang bersifat spatial diversity dengan memilih faktor pembobotan yang maksimal dari Signal Noise to Ratio yang diterima, dengan nilai error yang lebih rendah [7]

Beberapa penelitian yang telah dilakukan tentang penelitian ini antara lain adalah penelitian [8]. Hasil penelitian [8] menyatakan bahwa metode teknik maximal ratio combining merupakan pilihan paling tepat untuk mengatasi multipath fading yang berfungsi sebagai redaman sebagai penurunan performansi system. Sedangkan pada penelitian [9] diperoleh

p-ISSN:1693 - 2951; e-ISSN: 2503-2372 
bahwa teknik combining sebelumnya merupakan teknik terbaik dalam menangani multipath fading dimana teknik diversity Equal Gain Combining dan Selection Combining pada penerima mampu mengurangi BER ( Bit Error Rate ).

Penyebab yaitu sama adalah fading dimana Equal Gain Combining lebih baik daripada Selection Combining. Namun disebutkan masih terdapat kekurangan yang belum mampu di akomodasi oleh kedua teknik combining tersebut. Oleh karena itu beberapa penelitian [8], [9], [10], [11] lebih focus kepada performansi redaman dengan nilai Bit Error Rate agar terkontrol seminimal mungkin sehingga penelitian ini parameter pengujiannya adalah bit error rate yang diterima oleh penerima dengan kanal gelombang mikro untuk mengatasi multipath fading.

AWGN merupakan Salah satu jenis noise yang ada pada sistem komunikasi adalah noise thermal. Noise ini merusak sinyal dalam bentuk aditif, yaitu ditambahkan ke sinyal utama [12]. Sedangkan salah satu jenis noise ada yang bersifat addictive dimana noise akan menambah power spectral density dari sinyal transmisi, white artinya memiliki persebaran merata pada semua band, dan merupakan noiseyang terbangkitkan dengan distribusi Gaussian yaitu dengan nilai meannol dan standar deviasi bernilai satu [13]. AWGN merupakan noiseyang berada dan terjadi pada kanal rentang spektrum frekuensi dan merupakan noise thermal yang sifatnya menjumlah [14]. Noise ini terdiri dari seluruh frekuensi dalam spektralnya sebagai cahaya putih yang memiliki rapat spectraldaya yang konstan [15]. Pada kondisi ini, level sinyal yang diterima berubah terhadap waktu yang disebabkan oleh multipath [16]. Frekuensi tinggi dapat memberikan bandwidth yang lebar saat keadaan traffic rate tinggi [17]. Diversity juga digunakan untuk optimasi microwave link [18]. Fading mengalami penurunan atau pengurangan. Sedangkan dalam [19], digunakan teknik frequency diversity pada jaringan radio gelombang mikro melalui permukaan laut.

Phase Shift Keying (PSK) adalah salah satu modulasi dengan pengaruh beda fase yangtermodulasi di antara nilainilai yang ditetapkan sebelumnya. Frekuensi akan mengalami perubahan sehingga memberikan dampak status sinyal informasi digital yang membuat sudut fasa menjadi acuan di pemancar dan penerima. Oleh karena itu diperlukan stabilitas pada penerima sebab hubungan antara dua sudut fasa berpengaruh besar sehingga dapat dijadikan referensi. Transmisi berkecepatan tinggi yang akan digunakan pada sinyal digital maka menggunakan system modulasi PSK [20].

\section{DESIGN DAN KONFIGURASI}

Paragraf harus teratur. Semua paragraf harus rata, yaitu sama-sama rata kiri dan dan rata kanan.

Dalam perancangan jaringan gelombang mikro akan membandingkan unjuk kerja pengaruh Bit Error Rate saat sebelum diberikan teknik combining dan sesudah diberikan teknik combining tersebut.

Perancangan merupakan proses dalam mengimplementasikan teknik yang bervariasi dimana melibatkan deskripsi mengenai karakter detail komponen dan kelemahan yang akan dialami dalam proses pengerjaannya [22]. Parameter yang digunakan untuk menilai unjuk kerja transmisi digital pada penelitian adalah Bit Error rate. BER adalah perbandingan terhadap jumlah bit informasi yang diterima bersama jumlah bit informasi yang ditransmisikan pada selang waktu tertentu. Penggunaan matlab versi R2015.a dalam menunjukkan perbandingan bit error rate di penerima

\section{A. Gambaran Umum System}

Site yang dipakai adalah jaringan point-to point sehingga jalur yang digunakan murni gelombang mikro. Untuk perhitungan link budget pada gelombang mikro dan analisis system transmisi gelombang mikro pun disesuaikan dengan standard ITU-R tentang komunikasi short haul sehingga didapat nilai kisaran yang ideal. Perbandingan grafik yang ditampilkan pada simulasi adalah merupakan fungsi SNR ( Signal Noise To Ratio ) terhadap BER ( Bit Error Rate ). Secara formulasi pada perhitungan antara (Eb/No) dengan BER tergantung pada jenis modulasi yang digunakan yaitu dalam penelitian ini adalah Q-PSK. Dimana nilai (Eb/No) untuk sistem modulasi yang berlainan akan menghasilkan nilai BER yang berbeda.

\section{B. Blok Diagram}

Teknik diversity maximal combining ratio memiliki kelebihan yang lebih baik dalam system combining yang lain [21]. Gambar 1 menunjukkan konfigurasi ini untuk system ini menggunakan 2 noise. Kedua cabang-cabang ditimbang dengan rasio terhadap noise tertentu. Kemudian disatukan sebelum penjumlahan untuk memastikan bahwa semua cabang ditambahkan dalam fase untuk mendapatkan keragaman maksimum. Sinyal yang dijumlahkan kemudian digunakan sebagai menerima sinyal dan terhubung ke demodulator. Teknik maximal ratio combining akan selalu berkinerja lebih baik daripada Equal Gain Combining dan Selection Combining karena itu adalah combiner optimal [21]. Fading akan dibangkitkan bernilai konstan sepanjang satu interval bit, dimana jumlah fading yang terpicu saat dibangkitkan sama dengan jumlah bit input. Informasi pada semua saluran digunakan dengan teknik ini untuk mendapatkan sinyal yang diterima lebih dapat diandalkan. Kerugian dari teknik ini adalah itu rumit dan membutuhkan perkiraan akurat dari tingkat sinyal dan rata-rata kekuatan noise untuk mencapai kinerja optimal dengan skema kombinasi ini.

Sedangkan keuntungannya adalah perbaikan dapat dicapai dengan konfigurasi ini bahkan ketika keduanya cabang sepenuhnya berkorelasi. 


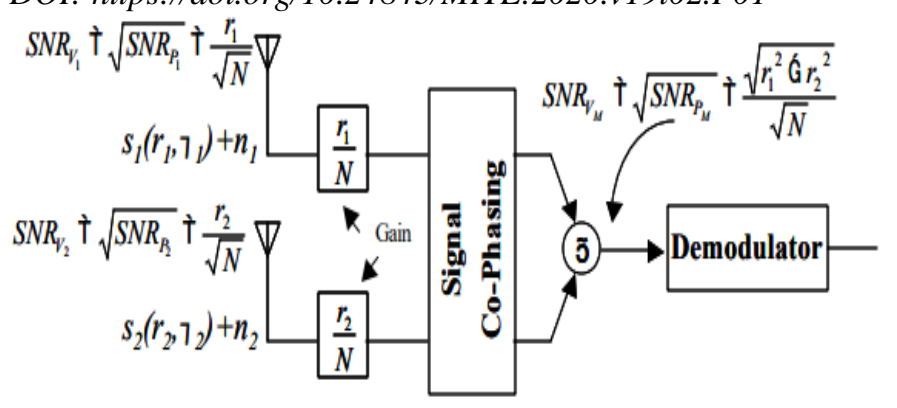

Gambar 1. Blok Diagram Teknik MRC dengan 2 kombinasi Noise

Signal Noise to Ratio pada alur MRC memerlukan evaluasi kekuatan sinyal sesaat dan daya noise. Amplitudo dari sinyal pada waktu tertentu t0, VS, M (t0), dapat dievaluasi dengan mengalikan sinyal yang diterima pada $r 1$ dan $r 2$, pada $t 0$, dengan penguatan sesaat ke rasio noise.

Penyebab interferens bersifat independen secara statistik, maka kapasitas kanal akan meningkat tanpa batas [24]. Dengan kata lain, efek kontaminasi tidak lagi menjadi faktor penghalang

Model kanal yang digunakan adalah Noise AWGN (Additive White Gaussian Noise). Noise di dalam pergerakan simulasi berdistribusi normal dengan nilai rata-rata adalah nol. Sifat dari noise ini bernilai acak sehingga kecenderungan menambahkan sinyal aslinya.

Bentuk persamaan dari distribusi Gaussian adalah [20]

$$
p(x)=\frac{1}{\sqrt{2 \pi \sigma}} e^{-\left(x-m_{x}\right)^{2} /\left(2 \sigma^{2}\right)}
$$

dimana :

$$
\begin{array}{ll}
\mathrm{x} & =\text { Variabel Acak } \\
m_{x} & =\text { mean } \\
\sigma^{2} & =\text { varians dari variable random }
\end{array}
$$

\section{Konfigurasi Simulasi Matlab}

Untuk mendapatkan level (magnitudo) simbol-simbol QPSK bernilai 1, maka nilai energi simbol yang diperlukan untuk memenuhi magnitudo $=1$ adalah E_s $=1$

Dibawah ini adalah model simulasi didasarkan pada teknik maximal ratio combining menggunakan modulasi Q-PSK dengan aturan AWGN .

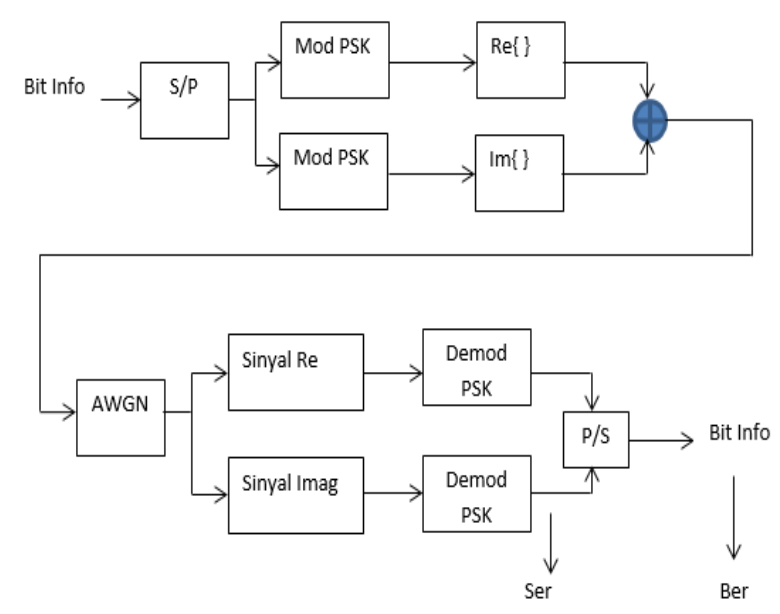

Gambar 2. Desain simulasi Matlab

Berdasarkan gambar simulasi diatas bit-info ditransmisikan secara bit bit seri to parallel menggunakan modulasi Q-PSK. Karena menggunakan jenis modulasi ini maka sesuai dengan diagram konstelasi (lihat gambar 3) bahwa sinyal yang berjalan menggunakan simbol riil dan imajiner.

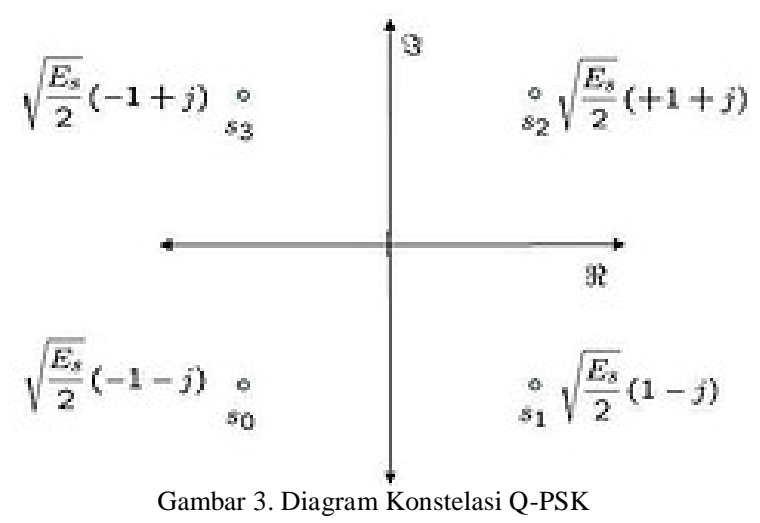

Setelah menjadi pembagian ini sebagai arah untuk memudahkan dalam pentransmisian. Dilewatkanlah AWGN dimana disinilah diberikan teknik diversity yaitu maximal ratio combining. Perhitungan AWGN selanjutnya symbol terbagi menjadi symbol riil dan imajiner. Setelah sudah pengkategorian maka dikembalikan atau demodulasi agar kembali menuju bit parallel to serial. Hal ini bertujuan untuk menjadikan bit kembali pada data yang diterima.

\section{Alur Penelitian}

Alur penelitian adalah sebagai berikut :

p-ISSN:1693 - 2951; e-ISSN: 2503-2372 


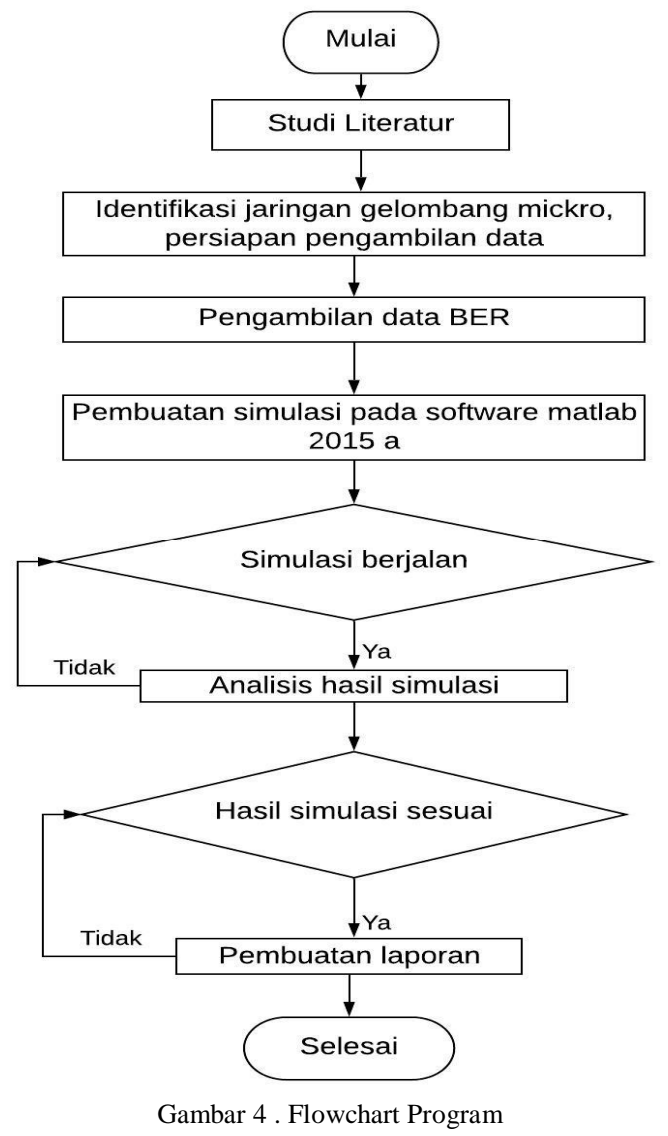

Ada beberapa langkah yang dilakukan yaitu :

1. Menggunakan beberapa literature baik yang berupa buku, jurnal, ataupun tulisan yang berhubungan dengan teknik diversity

2. Melakukan identifikasi jaringan komunikasi pada gelombang mikro dalam hal ini adalah menggunakan jenis modulasi BPSK atau QPSK

3. Pengambilan data Bit Error Rate adalah dalam BPSK namun jika dalam QPSK adalah Symbol Error rate yang akan dibandingkan dengan Es / No dalam dB.

4. Selanjutnya sistem akan menjalankan program untuk mensimulasi kan sesuai dengan skema yang dibuat menggunakan program Matlab 2015a.

5. Mentransformasikan simulasi program dalam bentuk grafik perbandingan yang membandingkan hasil simulasi dengan teori yang ada.

6. Display grafik yang diberikan merupakan beberapa nilai random dari bit yang dibangkitkan, oleh karena itu diberikan perhitungan nilai rata-rata sehingga mampu memberikan plotting grafik yang mengambil nilai rerata

Hubungan sinyal dan Varian Noise dinyatakan dengan persamaan [21] :

$$
\sigma^{2}=\frac{E N \_0}{2}
$$

Karena modulasi biner, maka E diganti dengan E_b

$$
\sigma^{2}=\frac{E b N \_0}{2}
$$

Diasumsikan E_b=1 agar amplitudo = 1, sedangkan saat ampitudo $=1$, sinyal yang dihasilkan sesuai dengan diagram konstelasi yang telah ditetapkan, yaitu A cos 0 (= 1 di sb x positif) dan $\mathrm{A} \cos 180$ (= -1 sb x negatif). Untk memenuhi nilai - 1 dan 1 dalam diagram konstelasi maka A harus bernilai 1 .

Untuk mendapatkan nilai perbandingan Eb/N0 yang meningkat (dalam grafik BER versus Eb/N0 ) karena $\mathrm{E} \_b=1$, maka nilai N0 harus dibuat semakin menurun. Untuk menurunkan nilai N0 maka nilai std (amplitudo atau level) noise hrs dibuat semakin menurun.

Untuk menurunkan nilai std noise, maka nilai Eb/N0 perlu ditingkatkan. Jadi, dengan membuat nilai Eb/N0 yang semakin meningkat dalam grafik BER versus Eb/N0, akan menurunkan nilai std noise, dan krn noise yang semakin kecil nilainya maka nilai Pe atau BER akan semakin menurun.

\section{HASIL DAN PEMBAHASAN}

\section{A. Analisis Kanal AWGN dengan BER modulasi Q-PSK}

Pada pengujian kanal AWGN dalam simulasi dibangkitkan jumlah data sebesar 100 Kbit $\left(\mathrm{N}=10^{6}\right)$. Jumlah yang dimaksudkan adalah BER minimum yang mungkin terjadi sekitar $10^{-4}$ sehingga memudahkan mendeteksi error.

Oleh karenanya jumlah bit pada simulasi harus lebih besar dari $\left(1 / 10^{-4}\right)$ atau $10^{4}$ bit. Pembangkitan dilakukan secara random dengan data yang dibangkitkan merupakan data bipolar yang memberikan nilai keluaran yang terdistribusi secara normal, dengan mean bernilai 0 .

Quadrature Phase Shift Keying (QPSK) dapat mengurangi daya pancar yang dibutuhkan atau, setara, meningkatkan jangkauan [23].

Data yang diterima oleh penerima sesuai dengan formulasinya merupakan penjumlahan dari data yang dikirim bersama noise AWGN. Perhitungan nilai BER dapat dilakukan dengan membandingkan pada jumlah bit dikirim saat mengalami error dan jumlah bit total yang dikirim.

Fungsi digunakan untuk menghitung jumlah error dengan tujuan membandingkan antara data yang dikirim dan diterima, sehingga didapat nilai yang mengalami eror. Untuk hasil pengujian dengan model kanal seperti dapat dilihat pada Gambar 5 


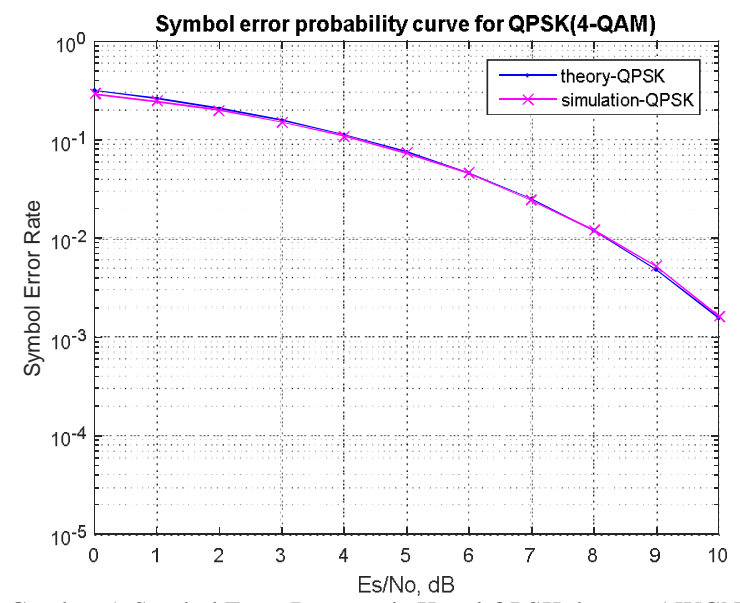

Gambar 5. Symbol Error Rate mode Kanal QPSK dengan AWGN

Berdasarkan gambar diatas, warna jingga adalah hasil dari produk simulasi QPSK dan warna Biru adalah produk dari teori QPSK. Didapat rerata garis yang hampir menempel dengan pembangkitan berdasarkan bit yang sudah diberikan sesuai gambar 2 .

Pada Gambar 5 dilakukan pengujian kinerja BER pada QPSK (SER) pada kanal AWGN dengan ketentuan antara lain, jumlah bit error akan di lakukan kontrol sehingga mendapatkan nilai simultan yang sama sesuai dengan teoritisnya.

\section{B. Pengujian Fading dengan Teknik Maximal Ratio Combining}

Pada pengujian ini menggunakan system 2 antena dimana berjalan di kanal fading sehingga diversitas spasial multi antenna dapat dibandingkan. Pada simulasi dilakukan pembangkitan data dengan fungsi sign (randn(1, $\mathrm{N}(\mathrm{i})$ )). Data yang dijadikan simulasi sebagai pemicu merupakan data bipolar, yaitu 1 atau -1 dengan distribusi normal dan mean bernilai 0 .

Noise yang akan dibangkitkan pada simulasi menggunakan teknik maximal ratio combining ini menggunakan noise AWGN dengan kanal fading.

Pada hasil simulasi terdapat maximal_ratio

1. SNR pada saluran 1 seharusnya $20 \mathrm{~dB}$. Sebenarnya adalah 20,05 dB

2. SNR pada saluran 2 seharusnya $15 \mathrm{~dB}$. Sebenarnya adalah $15,86 \mathrm{~dB}$

3. SNR pada saluran 3 seharusnya $12 \mathrm{~dB}$. Sebenarnya adalah $12,12 \mathrm{~dB}$

4. SNR setelah MRC seharusnya 21,7 dB. Sebenarnya adalah $21,72 \mathrm{~dB}$.

Debbi Irfan : Peningkatan Unjuk Kerja Pada Link ...
Data diatas didapat murni dari performa MRC terhadap noise AWGN dengan rerata yang dipakai. Noise yang memiliki nilai besar memberikan hasil SNR yang semakin kecil. Karena nilai dari noise berbanding terbalik dengan SNR. Begitu pula jika dekat jarak transmisi, maka akan semakin besar pula kekuatan SNR begitu pula sebaliknya.

Sedangkan untuk plotting hasil gambar yang didapatkan adalah sesuai gambar 6 .

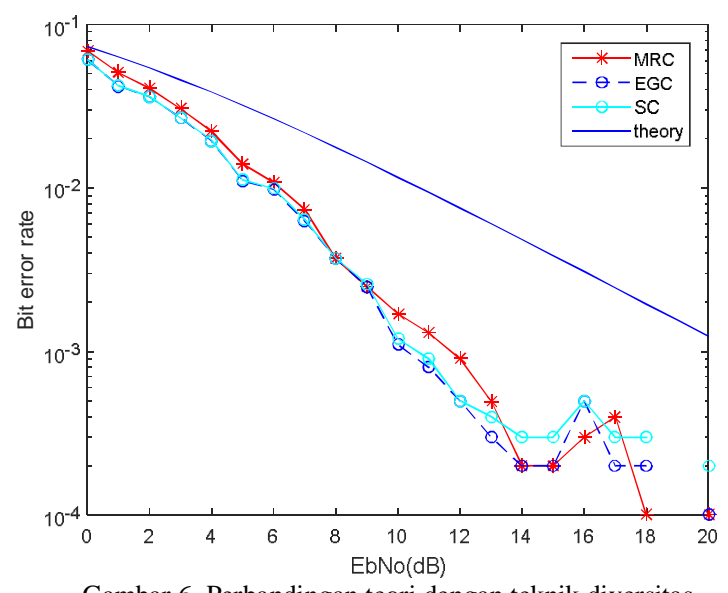

Berdasarkan gambar diatas, warna merah adalah hasil dari produk simulasi teknik MRC, sedangkan warna biru adalah teoritis perbedaan sebagai perbandingan. Antara lain ada metode diversitas lain selain maximal combining ratio yaitu equal gain combining dan selection combining.

Di plotting gambar juga disebutkan beberapa teori diversitas sebagai perbandingan. Didapat rerata garis yang hampir menempel serta naik turun dengan pembangkitan berdasarkan bit yang sudah diberikan.

\section{KESIMPULAN}

Pada pengujian BER di kanal AWGN dengan modulasi QPSK menggunakan teknik MRC dilakukan 3 kali sehingga didapatkan nilai BER pada Eb/No masing-masing $20.05 \mathrm{~dB}$, $14.86 \mathrm{~dB}, 12.12 \mathrm{~dB}$. Hasil pengujian BER di gelombang mikro pada kanal fading dengan diversitas spasial teknik maximal combining ratio lebih baik dibandingkan BER pada kanal fading tanpa ada diversitas antena. Sehingga metode diversitas dapat digunakan untuk memperbaiki BER pada kanal fading

\section{REFERENSI}

[1] Hourani, Hafeth, " An Overview of Diversity Techniques in Wireless Communication System", Helsinki University of Technology Communication Lab 2005

[2] E. N. Gilbert, "Capacity of a burst-noise channel," Bell Syst. Tech. J., pp. 1253-1265, (Sept. 1960)

[3] Baharuddin, "Peningkatan Unjuk Kerja Transmisi Citra Terkompresi Spiht Menggunakan Teknik Diversity Equal Gain Combining Pada

p-ISSN:1693 - 2951; e-ISSN: 2503-2372 
Daerah Frekuensi Radio" Jurnal Saintek Vol X Nomor 1. Terakreditasi, No. ISSN 1410-8070, pp. 95-106 september 2007.

[4] S. V. Kartalopoulos, "Per-port Statistical Estimation of Bit Error Rate and Optical Signal to Noise Ratio in DWDM Telecommunications," Noise Commun. Proc. SPIE, vol. 5473, 2004.

[5] A.C. Eska, "Komunikasi Bergerak Frekuensi $2.3 \mathrm{GHz}$ Melewati Pepohonan Menggunakan Metode Giovanelli Knife Edge," Jurnal Infotel, Vol. 8 No. 1, hal. 94-99, 2016

[6] A. Hikmaturokhman dan A. Wahyudin, Perancangan Jaringan Gelombang Mikro Menggunakan Pathloss 5: Teori dan Simulasi, Yogyakarta, Indonesia: Pustaka Ilmu, 2018.

[7] Aryanta, dkk, "Dynamic Spatial Diversity Combiner pada Kanal Fading" Jurnal ELKOMIKA Vol 7 Nomor 3. Halaman 466-479. September 2019

[8] Syahfrizal Tahcfulloh, "Penggunaan Maximal Ratio Combining ( MRC) Untuk Mengurangi Pengaruh Redaman Hujan dan Interferensi Pada Sistem Local Multipoint Distribution System Di Surabaya" https://www.researchgate.net/publication/323771771.

[9] Baharuddin, "Peningkatan Unjuk Kerja Transmisi Citra Terkompresi Spiht Menggunakan Teknik Diversity Equal Gain Combining Pada Daerah Frekuensi Radio" Jurnal Saintek Vol X Nomor 1. Terakreditasi, No. ISSN 1410-8070, pp. 95-106 september 2007.

[10] Willlyam Noveri. 2009. Analisis Pengaruh Teknik Diversity (Selective Combining dan Equal Gain Combining) Untuk Mengurangi Multipath Fading Sebagai Salah Satu Parameter Dalam Memperbaiki Bit Error Rate (BER). Tugas Akhir

[11] Aryanta, dkk, "Dynamic Spatial Diversity Combiner pada Kanal Fading" Jurnal ELKOMIKA Vol 7 Nomor 3. Halaman 466-479. September 2019

[12] Agus Maha., N. M. A. E. D. Wirastusi.. "Analisis Unjuk Kerja Improved Sinc Power Pulse pada Sistem OFDM Melalui Kanal Frequency Selective Fading”. Jurnal Teknologi Elektro. Vol. 18, No. 3. 2019.

[13] N. P. E. A. Yuniari., N. M. A. E. D. Wirastusi., I. G. A. K. D. D. Hartawan. "Analisis Perbandingan Performansi Sistem MC-SS MIMO dengan OFDM MIMO pada Kanal Fading”. Jurnal Teknologi Elektro. Vol. 15, No. 2. 2016.

[14] F. L. H. Utomo, N. M. A. E. D. Wirastuti, dan I. G. A. K. D. D. Hartawan, "Analisis Unjuk Kerja Coded OFDM Menggunakan Kode Convolutional Pada Kanal AWGN dan Rayleigh Fading," EJournal SPECTRUM., vol. 2, No. 2, Juni 2015.

[15] Agus Maha, N. M. A. E. D. Wirastuti. "Analisis Unjuk Kerja Convolutional Codepada Sistem MIMO MC-DSSS Melalui Kanal Rayleigh Fading," Jurnal Teknologi Elektro. Vol. 16, No. 2. 2017.

[16] K. Syahgustina, Simulasi dan Analisa Kinerja Sistem MIMO OFDM-FDMA Berdasarkan Alokasi Subcarrier, Fakultas Teknik Program Studi Teknik Elektro Universitas Indonesia: Depok, 2009

[17] S. Pramono, "Analisa Perencanaan Power Link Budget untuk Radio Microwave Point to Point Frekuensi 7 GHz (Studi Kasus : Semarang)," Jurnal Teknik Elektro Terapan, Vol. 3 No. 1, hal. 27-31, 2014.

[18] Z.H. Pradana dan A. Wahyudin, "Analisis Optimasi Space Diversity Pada Link Microwave Menggunakan Itu Models," Jurnal Elektro Telekomunikasi Terapan, Vol. 4 No. 2, hal. 586-592, 2017.

[19] Y. Rahmawati dan A. Wahyudin, "Perancangan Jaringan Backhaul Sistem Transmisi Gelombang Mikro Digital Menggunakan Frequency Diversity di Wilayah Kepulauan Riau," Techno, Vol. 19, pp. 63-70, 2018.

[20] Theodore. S. Rappaport. (2002). Wireless Communication Principles \& Practice. Prentice-Hall. Communications Engineering and Emerging Technologies Series.

[21] John G. Proakis, Digital Communciations, McGraw-Hill, New York, NY, 1995.

[22] Risky Soetam. "Konsep Dasar Rekayasa Perangkat Lunak”. Penerbit Prestasi Pustaka, Jakarta, 2011.

[23] Feng wang, Guijin, dkk. "Performance research of mPPM-QPSK modulation signal for free space optical communication" Optics Communications, Volume 457, article id. 124646. Februari 2020

[24] E. Björnson, J. Hoydis, dan L. Sanguinetti, "Massive MIMO Has Unlimited Capacity," IEEE Transactions on Wireless Communications, Vol. 17, No. 1, hal. 574-590, 2018. 